\title{
Factors Contributing to Low Tetanus Toxoid Vaccination Coverage among Young Adult Women in Khairpur District, Sindh
}

\author{
Suneel Raja ${ }^{1,2}$, Jaishri Mehraj ${ }^{1,3,4^{*}}$, Subhash Guriro ${ }^{5}$ and Muhammad Ali Shaikh \\ 'Department of Public Health, Shaheed Zulfikar Ali Bhutto Institute of Science and Technology (SZABIST), Karachi, \\ Sindh; suneelraja3@gmail.com \\ 2The United Nations Children's Fund, Country Office, Pakistan; jaishrimehraj@gmail.com \\ ${ }^{3}$ Emergency Operation Center for Polio Eradication and Immunization, Karachi Sindh, Pakistan \\ ${ }^{4}$ The Task Force for Global Health, Inc. TEPHINET Program, Pakistan \\ ${ }^{5}$ Sindh Madressatul Islam (SMI) University, Karachi, Pakistan; subhashg73@gmail.com, shaikh@smiu.edu.pk
}

\begin{abstract}
Background: Tetanus remains endemic in poor and developing countries since last decades as compared to rich and advanced countries. Low Tetanus Toxoid (TT) vaccination coverage has led to Tetanus related high morbidity and mortality amongst women and children in developing countries like Pakistan. Therefore, this study aims to assess the coverage of TT vaccination, knowledge about importance of TT vaccination and barriers to get full coverage among young women. Methodology: A cross-sectional study was conducted in district Khairpur among the female students of one Public Sector University. Total of 384 unmarried female students of more than 17 years of age were enrolled in the study. Information on vaccination status and different associated factors was collected through a questionnaire. We used logistic regression analysis to assess factors associated with vaccination status. Results: The mean age of study participants were 20.9 years with 2.15 standard deviation. Total of 311 (81\%) respondents had heard about TT vaccination and among 160 (41.7\%) major source of information was health care provider. Most of the respondents 303 (78.9\%) were considering Tetanus as a health problem. Furthermore, $141(36.7 \%)$ respondents knew that completion of 5 doses of TT vaccination can protect them from Tetanus disease. About $53 \%$ young women were vaccinated for TT including $11 \%$ fully vaccinated and $42 \%$ partially vaccinated. In multivariable model, those who were aware of Tetanus diseases were more likely to be vaccinated than those who had not heard about Tetanus disease (odds ratio 2.76: 95\% confidence interval; 1.19-6.43). Conclusion: We have found significant relationship of knowledge of Tetanus disease and vaccination coverage in the young adult women of Khairpur district. Study suggests the enhanced focus of government and other stakeholders on women's health education which can increase the uptake of vaccination among young women.
\end{abstract}

Keywords: Knowledge, Sindh, Vaccination, Tetanus Toxoid, Women

\section{Introduction}

Tetanus also known as a "Lockjaw" is a serious disease but it is preventable through the vaccination and safe delivery practices $\frac{1,2}{2}$. It affects the body's muscles as well as nervous system. Mortality from Tetanus is very high even under hospitalized care and it can range from $10 \%$ to $60 \%$ ․․․ There is limited access to health care facilities in remote areas and communities residing in these areas are prone to increased risk for Maternal and Neonatal Tetanus (MNT). Pakistan is among those eight countries of Asia and Africa where about $73 \%$ of neonatal Tetanus deaths occurs in comparison to other regions ${ }^{6}$.

*Author for correspondence 
About $54 \%$ women of reproductive age group receive at least two doses of Tetanus Toxoid (TT) vaccine during their last pregnancy in Pakistan ${ }^{7,8}$. In Sindh province of Pakistan, TT vaccination coverage is not optimal in pregnant women. Expanded Program on Immunization (EPI) Vaccine Preventable Diseases (VPDs) surveillance data shows that $70 \%-80 \%$ of women with neonatal Tetanus cases are un-vaccinated ${ }^{9,10}$. In order to endure Maternal and Neonatal Tetanus (MNT) elimination, countries require forming and retaining a strong routine immunization program along with promoting clean delivery practices $\frac{11,12}{1}$.

Within 12 high risks districts of Sindh Province regarding MNT, District Khairpur is one of those where coverage is not more than $50 \%$ and continuously reporting the cases of neonatal Tetanus cases ${ }^{10}$. District level surveillance structure is also weak and could not capture the cases, deaths and outbreaks of other VPDs. Besides, community response and awareness, service delivery system is reported to be weak to cater the target population for Tetanus vaccination. Despite tremendous efforts and achievement, quality of data and coverage are still greater challenges for government and international stakeholders. Most of the studies were conducted previously in urban settings and very few were conducted in the rural areas of Sindh province in Pakistan $\frac{78,13}{\text {. This research }}$ study was carried out to investigate the TT vaccination status among young adult woman in Khairpur district and to find out TT vaccination status and factors associated with low coverage among unmarried women.

\section{Methodology}

A cross-sectional study has been conducted to assess the TT vaccination status among unmarried university students of age 18 years and above in one of the Public Sector University of district Khairpur in Sindh Province, Pakistan. Study was conducted during the period of March to May 2017. Khairpur is one of the largest districts of Sindh province with total population of 2,404,334 and an estimated 459,007 women of child bearing age $\mathrm{e}^{14}$.

Data was collected through female workers in the area. Simple random technique was used to select study participants. Prior to data collection, consent form was taken from each participant and then a questionnaire based on different questions on various factors was completed from selected participants. The data was analyzed on software IBM SPSS version 21. Descriptive analysis has been used to calculate mean and standard deviation for continuous variables and proportions for categorical variables. The frequencies with percentages were calculated of categorical variables such as vaccination status, vaccination card retention, socio-economic status like household status, owned, rented and number of rooms in the household and knowledge related questions. Inferential analysis was done to check relationship of vaccination status with different independent variables through Chi square test. Logistic regression analysis was conducted to determine the association of vaccination status with knowledge related factors. Ethical approval was obtained from the Institutional ethics Review Board (IRB) of Shaheed Zulfikar Ali Bhutto Institute of Science and Technology (SZABIST), Karachi, Sindh.

\section{Results}

A total number of 384 women of more than 17 years of age were enrolled in the study. The mean age \pm Standard Deviation (SD) of the study participants was $20.9 \pm 2.15$ years (range 18-27 years). The majority 205 (53.4\%) participant were in age group of 18-20 years, followed by 176 $(45.8 \%)$ in $21-25$ years category and $3(0.8 \%)$ more than 25 years. Among the study subjects 338 (88.0\%) were graduates. About 192 (50.0\%) participants were from Natural Science field of studies while 147 (38.3\%) participants were from Arts \& Commerce. Education status of family members shows that most of the mothers of participants 180 (46.9\%) were illiterate and 337 (87.8\%) were Housewives. Whereas, most of the fathers of respondent's $164(42.7 \%)$ were graduate and above and 145 (37.8\%) were Government Servant (Table1).

Table 1. Demographic and socioeconomics characteristics of young adult women of district Khairpur, Sindh

\begin{tabular}{|l|l|l|}
\hline Characteristics & $\begin{array}{l}\text { Frequency } \\
(\mathbf{3 8 4})\end{array}$ & $\%$ \\
\hline Age of Respondent & & \\
\hline $18-20$ years & 205 & 53 \\
\hline $21-25$ years & 176 & 45 \\
\hline$>25$ years & 3 & 0 \\
\hline Age Mean \pm Standard Deviation & 20.9 & 2.15 \\
\hline Education of Respondent & & \\
\hline
\end{tabular}




\begin{tabular}{|c|c|c|}
\hline Graduation & 338 & 88 \\
\hline Masters & 46 & 12 \\
\hline \multicolumn{3}{|l|}{ Field of education } \\
\hline Natural Science & 192 & 50 \\
\hline Social Science & 45 & 11.7 \\
\hline Arts \& Commerce & 147 & 38.3 \\
\hline \multicolumn{3}{|l|}{ Education of mother } \\
\hline Illiterate & 180 & 46.9 \\
\hline Primary to 8 th grade & 56 & 14.6 \\
\hline Secondary & 73 & 19 \\
\hline Higher secondary & 32 & 8.3 \\
\hline Graduate and above & 43 & 11.2 \\
\hline \multicolumn{3}{|l|}{ Occupation of mother } \\
\hline Own business & 2 & 0 \\
\hline Private Job & 24 & 6 \\
\hline Government Servant & 21 & 5 \\
\hline House wife & 337 & 87 \\
\hline \multicolumn{3}{|l|}{ Education of father } \\
\hline Illiterate & 70 & 18 \\
\hline Primary to 8th grade & 18 & 4 \\
\hline Secondary & 54 & 14 \\
\hline Higher secondary & 78 & 20 \\
\hline Graduate and above & 164 & 42 \\
\hline \multicolumn{3}{|l|}{ Occupation of father } \\
\hline Own business & 99 & 25.8 \\
\hline Private Job & 73 & 19 \\
\hline Government Servant & 145 & 37.8 \\
\hline Landlord & 18 & 4.7 \\
\hline Unemployed & 26 & 6.8 \\
\hline Retire & 23 & 6 \\
\hline \multicolumn{3}{|c|}{ House status of respondent } \\
\hline Owned & 272 & 70 \\
\hline Rented & 106 & 27 \\
\hline Living with paying rent & 6 & 1 \\
\hline \multicolumn{3}{|c|}{ Number of household rooms } \\
\hline One & 49 & 12 \\
\hline Two & 156 & 40 \\
\hline Three & 130 & 33 \\
\hline Four or more & 49 & 12 \\
\hline
\end{tabular}

Total of 311 (81\%) respondents had heard about TT vaccination and 160 (41.7\%) major source of information was health care provider. Most of the respondents 303 (78.9\%) were considering Tetanus as a health problem. Furthermore, 141 (36.7\%) respondents knew that completion of five doses of Tetanus Toxoid vaccination can protect them from Tetanus disease (Table 2).

Table 2. Knowledge of young adult women of district Khairpur, Sindh about tetanus toxoid vaccination

\begin{tabular}{|c|c|c|}
\hline $\begin{array}{l}\text { Knowledge about Tetanus } \\
\text { Toxoid Vaccination }\end{array}$ & $\begin{array}{l}\text { Frequency } \\
(384)\end{array}$ & $\%$ \\
\hline \multicolumn{3}{|c|}{ Heard about Tetanus Toxoid Vaccination } \\
\hline Yes & 311 & 81.0 \\
\hline No & 73 & 19.0 \\
\hline \multicolumn{3}{|l|}{ Where did you hear from } \\
\hline Media & 99 & 25.8 \\
\hline Local leaders & 25 & 6.5 \\
\hline Religious leaders & 11 & 2.9 \\
\hline Healthcare provider & 160 & 41.7 \\
\hline Don't know & 89 & 23.2 \\
\hline \multicolumn{3}{|l|}{ Tetanus is a health problem } \\
\hline Yes & 303 & 78 \\
\hline No & 16 & 4 \\
\hline Don't know & 65 & 16 \\
\hline \multicolumn{3}{|l|}{ When Tetanus occurs } \\
\hline During Pregnancy & 80 & 20 \\
\hline After Pregnancy & 52 & 13 \\
\hline New-born at time of birth & 53 & 13 \\
\hline $\begin{array}{l}\text { At the time of umbilical cord } \\
\text { cutting }\end{array}$ & 29 & 7 \\
\hline Mother of newborn baby & 37 & 9 \\
\hline Don't know & 133 & 34 \\
\hline \multicolumn{3}{|c|}{$\begin{array}{l}\text { Duration of protection after } 5 \text { doses of Tetanus Toxoid } \\
\text { vaccination }\end{array}$} \\
\hline $0-2$ years & 38 & 9 \\
\hline $2-5$ years & 26 & 6 \\
\hline More than 5 years & 38 & 9 \\
\hline More than 10 years & 40 & 10 \\
\hline For life & 141 & 36 \\
\hline Don't know & 101 & 26 \\
\hline
\end{tabular}




\begin{tabular}{|c|c|c|}
\hline $\begin{array}{c}\text { Tetanus Toxoid } \\
\text { Vaccination Status }\end{array}$ & Number & $\%$ \\
\hline No Vaccination & 180 & 46.9 \\
\hline TT - 1 & 69 & 18.0 \\
\hline TT - 2 & 53 & 13.8 \\
\hline TT - 3 & 26 & 6.8 \\
\hline TT - 4 & 15 & 3.9 \\
\hline TT - 5 & 41 & 10.7 \\
\hline \hline
\end{tabular}

Vaccinatoin Status of Respondents

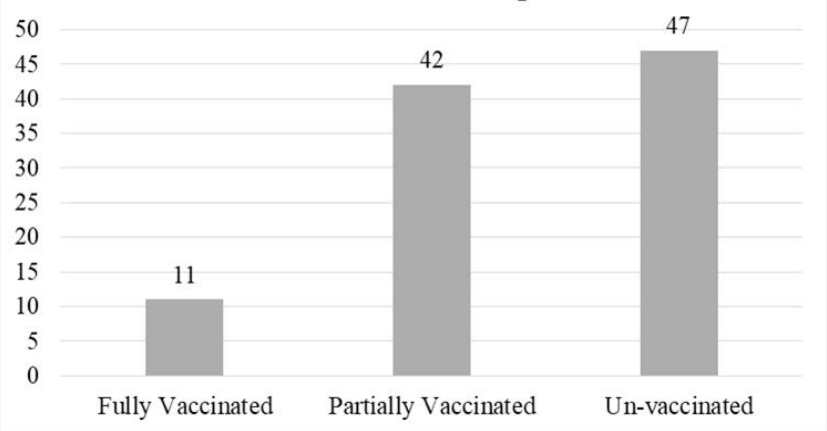

Figure 1. Tetanus Toxoid Vaccination status of young adult women of district Khairpur, Sindh.

About 204 (53.1\%) young women were vaccinated for TT including 41 (10.7\%) fully vaccinated and 163 (42.4\%) partially vaccinated. Among the 204 participants vaccinated for $\mathrm{TT}$, majority of participants 69 (33.8\%) received one dose of TT, 53 (26.0\%) second doses of TT, 26 (12.7\%) third doses of TT, 15 (7.4\%) four doses of TT and only 41 (20.1\%) received complete five doses (Figure 1). Respondents also agreed that increase in education will lead to an increase in the TT vaccination. Moreover, $59 \%$ respondents have agreed to increase the education of women, $61 \%$ community leaders, $47 \%$ religious leaders and $63 \%$ media as a source for increasing awareness and TT vaccination in the community (Figure 2 ).

In response to question that whether the unmarried women of child bearing age need TT vaccination, $66 \%$ participants replied yes. When participants were asked to give their opinion on their preference regarding taking vaccination dose, $77 \%$ of participants shared that they would like to prefer female vaccinator while $23 \%$ shared male vaccinator. Results show that those participants who were considering Tetanus as health problem are more likely to get vaccination. About $62.4 \%$ participants considering Tetanus as health problem and got vaccinated while $81.3 \%$ do not considered it as a problem and did not get vaccinated.

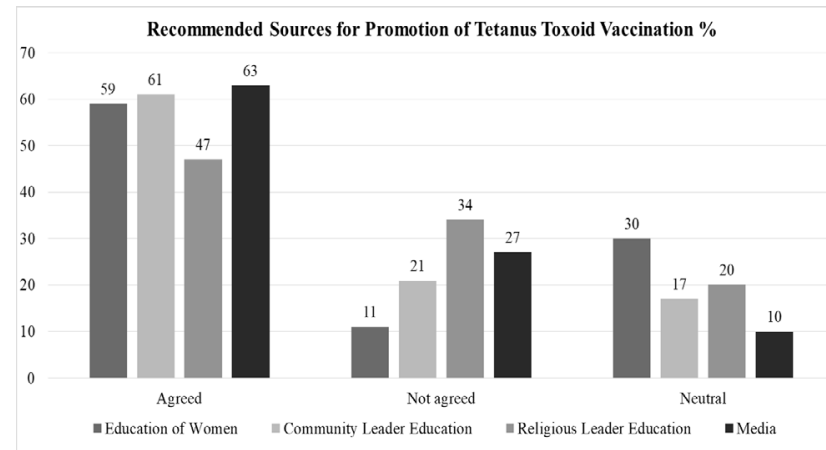

Figure 2. Recommendations for promotion of tetanus toxoid vaccination status of young adult women of district Khairpur, Sindh.

In addition, factors associated with $\mathrm{TT}$ vaccination status were determined through logistic regression. The knowledge related factors were found statistically significant in the multivariable analysis. In multivariable model, those who heard of Tetanus diseases were OR 2.76 (95\% CI; 1.19-6.43) more likely to be vaccinated to TT than those who had not heard about Tetanus disease (Table 3 ).

\section{Discussion}

The purpose of this study was to assess the reasons for low coverage of Tetanus among unmarried females in Pakistan. In our study we found $42 \%$ partially immunized (vaccination from one dose to four doses) unmarried women in Khairpur district. It was alarming that only 11 $\%$ of the participants had completed five doses of TT vaccination. Vaccination status was $18 \%$ for first dose, $14 \%$ for second dose, $7 \%$ for third dose, $4 \%$ for forth and $11 \%$ for five doses respectively. Thus, results show that there is a significant dropout rate observed in study participants. Among total participants $81 \%$ young women had knowledge about TT vaccination and $79 \%$ participants considered Tetanus as a health problem. Previously awareness regarding vaccination was noted more than $92 \%$ among students of Karachi University, one of the highly urbanized area ${ }^{15}$. Higher awareness level about TT vaccination may be associated with higher education level of participants as $88 \%$ completed graduation and $12 \%$ were master's students in Karachi University. Based on results, it can be said that continuous health education is required to improve the coverage. On the other hand, TT vaccination coverage among university students reported in a study conducted in Karachi showed that 41(3\%) received 
Table 3. Association of knowledge level and vaccination status of young adult women of district Khairpur, Sindh about Tetanus Toxoid Vaccination

\begin{tabular}{|c|c|c|c|c|c|c|}
\hline \multirow{2}{*}{ Variables } & \multicolumn{2}{|c|}{ Tetanus Toxoid vaccination } & \multicolumn{2}{|l|}{ Unadjusted } & \multicolumn{2}{|l|}{ Adjusted } \\
\hline & Yes & No & OR (95\% CIs) & $\mathrm{P}$-value & OR (95\% CIs) & P-value \\
\hline $\begin{array}{l}\text { Heard about Tetanus } \\
\text { No } \\
\text { Yes }\end{array}$ & \begin{tabular}{|l}
$13(6.4)$ \\
$191(93.6)$ \\
\end{tabular} & $\begin{array}{l}60(33.3) \\
120(66.7) \\
\end{array}$ & $\begin{array}{l}1 \\
7.35(3.87-13.95)\end{array}$ & $<0.0001$ & $\begin{array}{l}1 \\
2.76(1.19-6.43)\end{array}$ & 0.018 \\
\hline $\begin{array}{l}\text { Tetanus is a health } \\
\text { problem } \\
\text { No } \\
\text { Yes } \\
\text { Don't know }\end{array}$ & $\begin{array}{l}3(1.5) \\
189(92.6) \\
12(5.9)\end{array}$ & $\begin{array}{l}13(7.2) \\
114(63.3) \\
53(29.4)\end{array}$ & $\begin{array}{l}1 \\
7.18(2.00-25.75) \\
0.98(0.24-3.99)\end{array}$ & $\begin{array}{l}0.002 \\
0.979\end{array}$ & $\begin{array}{l}1 \\
3.84(0.9-16.36) \\
1.77(0.38-8.32)\end{array}$ & $\begin{array}{l}0.069 \\
0.471\end{array}$ \\
\hline $\begin{array}{l}\text { When Tetanus occurs } \\
\text { Don't know } \\
\text { During Pregnancy } \\
\text { After Pregnancy } \\
\text { New-born at time of birth } \\
\text { At the time of umbilical } \\
\text { cord cutting } \\
\text { Mother of newborn baby }\end{array}$ & $\begin{array}{l}42(20.6) \\
58(28.4) \\
32(15.7) \\
34(16.7) \\
16(7.8) \\
22(10.8)\end{array}$ & $\begin{array}{l}91(50.6) \\
22(12.2) \\
20(11.1) \\
19(10.6) \\
13(7.2) \\
15(8.3)\end{array}$ & $\begin{array}{l}1 \\
5.72(3.09-10.53) \\
3.47(1.78-6.76) \\
3.88(1.98-7.58) \\
2.67(1.18-6.04) \\
3.18(1.49-6.74)\end{array}$ & $\begin{array}{l}<0.0001 \\
<0.0001 \\
<0.0001 \\
0.019 \\
0.003\end{array}$ & $\begin{array}{l}1 \\
2.18(1.01-4.671) \\
1.61(0.69-3.77) \\
2.82(1.18-6.76) \\
2.01(0.72-5.61) \\
2.36(0.9-6.19)\end{array}$ & $\begin{array}{l}0.046 \\
0.269 \\
0.02 \\
0.181 \\
0.081\end{array}$ \\
\hline $\begin{array}{l}\text { Protection from Tetanus } \\
\text { after } 5 \text { doses of Tetanus } \\
\text { Toxoid vaccination } \\
\text { Don't know } \\
0-2 \text { years } \\
2-5 \text { years } \\
\text { More than } 5 \text { years } \\
\text { More than } 10 \text { years } \\
\text { For life }\end{array}$ & $\begin{array}{l}30(14.7) \\
24(11.8) \\
12(5.9) \\
15(7.4) \\
23(11.3) \\
100(49)\end{array}$ & $\begin{array}{l}71(39.4) \\
14(7.8) \\
14(7.8) \\
23(12.8) \\
17(9.4) \\
41(22.8)\end{array}$ & $\begin{array}{l}1 \\
4.057(1.85-8.897) \\
2.029(0.84-4.897) \\
1.543(0.709-3.36) \\
3.202(1.5-6.836) \\
5.772(3.295-10.111)\end{array}$ & $\begin{array}{l}<0.0001 \\
0.116 \\
0.274 \\
0.003 \\
<0.0001\end{array}$ & $\begin{array}{l}1 \\
1.386(0.509-3.774) \\
0.949(0.307-2.928) \\
0.709(0.262-1.919) \\
1.506(0.563-4.026) \\
2.212(1.017-4.812)\end{array}$ & $\begin{array}{l}0.523 \\
0.927 \\
0.499 \\
0.414 \\
0.045\end{array}$ \\
\hline
\end{tabular}

${ }^{\star}$ Variable with P-value $\leq 0.25$ were taken for multivariable model.

complete course of five doses shows low trend of complete vaccination among woman of reproductive age $\mathrm{i}^{15}$. Likely in a cross-sectional study conducted with a sample of 646 married and unmarried women in Peshawar city of Pakistan reported 55\% coverage among women of child bearing age ${ }^{\frac{16}{6}}$. Tetanus coverage in Bangladesh is better as compared to Pakistan ${ }^{17}$. A research study conducted in 2012 revealed coverage from TT1 to TT4 at $84 \%$ to $46 \%$ respectively. Also noted that rural area women of reproductive age never received TT5 and dropout rate was higher $\frac{18}{}$. Low coverage of TT vaccination among married women may be due to poor knowledge and importance about the TT vaccination as observed in previous study. In this study $87 \%$ women were reported as vaccinated with two doses based on their recall ${ }^{19}$. Lack of awareness and importance is due to misconception about TT among the study participants ${ }^{20}$.
Low coverage in Karachi may be due to absence of campaigns of MNT Elimination Program. Similar findings also reported in a Nigeria University where only $18 \%$ respondents knew that $\mathrm{TT}$ vaccination given to unmarried and majority of respondent knew that TT vaccination campaigns only targeting -married women of reproductive age ${ }^{21}$. Moreover, study suggested that those students who have knowledge about TT vaccination have more chance of getting vaccination 22 .

We have observed in Khairpur district that fully immunization coverage for five doses remained low as $11 \%$ which needs attention and follow up strategies by the EPI related healthcare Centers. We asked for the sharing details of the vaccination card from those participants who were vaccinated against Tetanus. Majority of respondents shared that they have no vaccination card while only $34 \%$ had vaccination card. We observed this cover- 
age proportion which can be the result of supplementary campaigns conducted by UNICEF under Elimination of MNT Program in Khairpur district $\underline{23}$.

In our study, major source of information among participnats regarding the TT vaccination was the health workers with $42 \%$ in comparison with $26 \%$ responses in favor of media and this finding is comparable with other studies as well. A study in Nigeria has mentioned that the most common source of information regarding TT is the health worker in area ${ }^{21}$. Similar finding is also mentioned in a cross-sectional study in Peshawar that major source of information for Tetanus is the healthcare provider ${ }^{19}$. Only $6 \%$ participants reported about relative or friend in the health care but its association with outcome variable was insignificant. Those participants who knew the importance of completing TT vaccination will have more vaccination coverage as significant association was observed. Similarly in a study in India has shown positive relationship between higher education and knowledge about prevention ${ }^{24}$. It was also confirmed by a study in Nigeria that $60 \%$ of students knew that TT vaccination was effective in preventing from Tetanus disease. Partial coverage was reported in $54 \%$ participants while $14 \%$ women were fully immunized who received five doses $\frac{21,22}{}$. Similarly finding also reported by a study where $85 \%$ coverage observed in rural community in Bangladesh in the age group of 20-24 years of women $\frac{18}{}$.

Khairpur district, each participant of this study was asked that how the knowledge of eligible groups to uptake the TT vaccination can be improved in district. In this connection majority of respondents were in favor of providing the health education to the women of child bearing age. When it was assessed that what is the preference for vaccinator, the majority $77 \%$ participants responded that they were easy to get vaccination from female vaccinator. This observation can lead to more vaccination coverage if -induction of female vaccinators is ensured in remote areas. Due to cultural barriers, female vaccinator would be more effective as compared to male vaccinators ${ }^{25}$. In this connection, EPI department of Government should review its recruitment policy and take other measures for TT coverage as identified in this study.

\section{Conclusion}

This study has revealed that coverage of Tetanus is not up to the mark in Khairpur district of Sindh province in Pakistan. We have noted half of the females of reproductive age are unvaccinated and complete five dose vaccination status is lower than partially vaccinated women who have received one to four doses of TT vaccine. Furthermore, this study has identified significant relationship of low vaccination coverage to knowledge of participants regarding Tetanus in study area. Study revealed that there are more likely chances of high coverage of TT in those women who consider Tetanus as health problem and understands the importance of TT vaccination for unmarried women. In this scenario, supplementary vaccination campaigns with strong health education for women needs to be focused to increase the uptake of vaccination among unmarried women. There is a strong need to engage media for public awareness for vaccination of Tetanus in rural settings of province and Expanded Program on Immunization, Government of Sindh has to revise its strategy and practices for full coverage of vaccination.

\section{Acknowledgements}

This manuscript is part of Master of Public Health (MPH) thesis of Mr. Suneel Raja. The authors are grateful to all the respondents who participated in this research.

\section{Competing Interests}

Authors declare there is no conflict of interest.

\section{References}

1. Maternal and Neonatal Tetanus Elimination (MNTE). The initiative and challenges. Date accessed: 2015. https://www. who.int/immunization/diseases/MNTE_initiative/en/.

2. Wilson RJ, Paterson P, Jarrett C, Larson HJ. Understanding factors influencing vaccination acceptance during pregnancy globally: A literature review, Vaccine. 2015; 33(47):6420-29. https://doi.org/10.1016/j.vaccine.2015.08.046. PMid: 26320417.

3. Thwaites CL, Beeching NJ, Newton CR. Maternal and neonatal tetanus, The Lancet. 2015; 385(9965):362-70. https:// doi.org/10.1016/S0140-6736(14)60236-1.

4. Hasnain S, Sheikh NH. Causes of low tetanus toxoid vaccination coverage in pregnant women in Lahore district, Pakistan, Eastern Mediterranean Health Journal. 2007; 13(5):1142-52. https://doi.org/10.26719/2007.13.5.1142. PMid: 18290408. 
5. Esen B, Kurtoglu D, Coplu N, Gozalan A, Miyamura K, Ishida S, Akin L. Tetanus immunization status among women of childbearing age in Turkey, Japanese Journal of Infectious Diseases. 2007; 60(2/3):92-96.

6. Anatea MD, Mekonnen TH, Dachew BA. Determinants and perceptions of the utilization of tetanus toxoid immunization among reproductive-age women in Dukem Town, Eastern Ethiopia: a community-based cross-sectional study. BMC international health and human rights. 2018, 18 (1), pp. 27. https://doi.org/10.1186/s12914-018-0168-0. PMid: 29950171, PMCid: PMC6022706.

7. Quddus A, Luby S, Rahbar M, Pervaiz Y. Neonatal tetanus: mortality rate and risk factors in Loralai District, Pakistan, International Journal of Epidemiology. 2002; 31(3):648-53. https://doi.org/10.1093/ije/31.3.648. PMid: 12055169.

8. Nisar N, Aziz N, Mumtaz F. Tetanus toxoid vaccination coverage among pregnant women at tertiary care hospital, Sindh Pakistan, Med. Channel. 2010; 16(2):272-25.

9. Pakistan Demographic and Health Survey 2012-13. Date accessed: 2012. https://dhsprogram.com/pubs/pdf/fr290/ fr290.pdf.

10. Expanded Program on Immunization. Date accessed: 2016. http://www.emro.who.int/pak/programmes/expandedprogramme-on-immunization.html.

11. Lambo JA, Nagulesapillai T. Neonatal tetanus elimination in Pakistan: Progress and challenges, International Journal of Infectious Diseases. 2012; 16(12):833-42. https://doi. org/10.1016/j.ijid.2012.07.015. PMid: 22940280.

12. Khan R, Vandelaer J, Yakubu A, Raza AA, Zulu F. Maternal and neonatal tetanus elimination: from protecting women and newborns to protecting all, International Journal of Women's Health. 2015; 7:171-80. https://doi.org/10.2147/ IJWH.S50539. PMid: 25678822, PMCid: PMC4322871.

13. Ahmed SI, Baig L, Thaver IH, Siddiqui MI, Jafery SI, Javed A. Knowledge, attitudes and practices of general practitioners in Karachi District Central about tetanus immunization in adults, Journal of Pakistan Medical Association. 2001; 51(10):367-69.

14. Pakistan Bureau of Statistics. Date accessed: 2017. http:// www.pbs.gov.pk/.

15. Qadir M, Murad R, Mumtaz S, Azmi AA, Rehman R, Aziz $\mathrm{N}$. Frequency of tetanus toxoid immunization among college/university female students of Karachi, Journal of Ayub Medical College Abbottabad. 2010; 22(1):147-49.

16. Naeem M, Khan MZ, Abbas SH, Adil M, Khan A, Naz SM, Khan MU. Coverage and factors associated with tetanus toxoid vaccination among married women of reproductive age: A cross sectional study in Peshawar, Journal of Ayub Medical College Abbottabad. 2010; 22(3):136-40.

17. Tanjida S, Huq SA, Sudhira B, Nahida S. Status of knowledge and practice about complete tetanus toxoid immunization of unmarried female students of a public university in Dhaka, Bangladesh Journal of Medical Science. 2009; 8(4):102-09. https://doi.org/10.3329/bjms.v8i4.4707.

18. Islam MZ, Ahmed MS, Ahmed N, Farjana S, Mazumder SK. Tetanus toxoid vaccination coverage among women of reproductive age: Experience from a rural community, Bangladesh Medical Journal. 2012; 41(1):37-41. https:// doi.org/10.3329/bmj.v41i1.18780.

19. Afridi NK, Hatcher J, Mahmud S, Nanan D. Toxoid vaccination status among females of reproductive age in Peshawar, Journal of College of Physicians and Surgeons. 2005; 15(7):391-95.

20. Anokye M, Amoah-Mensah J, Osei Frimpong F, Acheampong N. Immunization Coverage of Pregnant Women with Tetanus Toxoid Vaccine in Dormaa East District-Brong Ahafo Region, Ghana, In International Conference on Applied Science and Technology Conference Proceedings. 2017, 3(1):106-15.

21. Alex-Hart BA, Okoh BA. Awareness and status of tetanus toxoid vaccination among female undergraduate students in a Nigerian University, International Journal of Tropical Disease and Health. 2015; 7(1):6-15. https://doi. org/10.9734/IJTDH/2015/15468.

22. Sule SS, Nkem-Uchendu C, Onajole AT, Ogunowo BE. Awareness, perception and coverage of tetanus immunisation in women of child bearing age in an urban district of Lagos, Nigeria, The Nigerian Postgraduate Medical Journal. 2014; 21(2):107-14.

23. Khan EA, Khan R, Iqbal MT, Hasan Q, Farrukh S, Rana MS, Khan WM. Risk characterization of maternal and neonatal tetanus in view of tetanus vaccination campaigns in Pakistan, Journal of Ayub Medical College Abbottabad. 2015; 27(1):220-22.

24. Verma R, Khanna P. Tetanus toxoid vaccine: elimination of neonatal tetanus in selected states of India, Human Vaccines and Immunotherapeutic. 2012; 8(10):1439-42. https://doi.org/10.4161/hv.21145. PMid: 22894950, PMCid: PMC3660763.

25. Khan AA, Zahidie A, Rabbani F. Interventions to reduce neonatal mortality from neonatal tetanus in low and middle income countries-a systematic review, BMC Public Health. 2013; 13(1):322. https://doi.org/10.1186/1471-2458-13-322 PMid: 23570611, PMCid: PMC3637612. 